Article

\title{
Electrical Properties of Silver-Attached Amine Functionalized Carbon Black/Polyethylene Terephthalate Fibers Prepared by Melt-Spinning
}

\author{
Hyun-Jung Choi ${ }^{1}$, Damiro Ahn ${ }^{1}$, Sohee Lee ${ }^{2}$ (I) and Sang Young Yeo ${ }^{1, *}$ \\ 1 Technical Textile Materials R\&D Group, Korea Institute of Industrial Technology, 143 Hanggaulro, \\ Sangnok-gu, Ansan-si, Gyeonggi-do 15588, Korea; hjchoi@kitech.re.kr (H.-J.C.); \\ ahndamiro94@kitech.re.kr (D.A.) \\ 2 Department of Clothing and Textiles, Research Institute of Natural Science, Gyeongsang National University, \\ 501 Jinju-dearo, Jinju-si, South Gyeongsang Province 52828, Korea; sohee.lee@gnu.ac.kr \\ * Correspondence: miracle@kitech.re.kr; Tel.: +82-31-8040-6068
}

Received: 9 September 2019; Accepted: 30 September 2019; Published: 3 October 2019

check for updates

\begin{abstract}
In this study, amine functionalized carbon black $(\mathrm{ABCB})$ was synthesized using 4-aminobenzoic acid in a phosphoric acid (PPA)/phosphorus pentoxide $\left(\mathrm{P}_{2} \mathrm{O}_{5}\right)$ medium, and silver-attached carbon black $(\mathrm{Ag}-\mathrm{ABCB})$ was prepared by reducing $\mathrm{AgNO}_{3}$ with $\mathrm{NaBH}_{4}$ in the presence of $\mathrm{ABCB}$ in ethanol. Elemental, thermogravimetric, and Fourier transform-infrared analyses showed that carbon black (CB) had a well-functionalized 4-aminobenzoic acid. In addition, X-ray photoelectron spectroscopy and X-ray diffraction were used to examine the crystal structure of Ag nanoparticles. Conductive fibers were prepared by melt-spinning using ABCB, Ag-ABCB as a conductive filler, and polyethylene terephthalate (PET) as a polymer matrix. Results confirmed that the fiber that had Ag-ABCB as a conductive filler exhibited the best electrical conductivity. The dispersibility and morphology of the conductive filler in the PET matrix were confirmed through scanning electron microscopy analysis, and Ag-ABCB was the most uniformly dispersed filler in the PET matrix, with good structure.
\end{abstract}

Keywords: conductive fiber; melt-spinning; silver nanoparticle; carbon black; PET

\section{Introduction}

As technology continues to improve, new conductive materials for thinner, lighter, and more portable displays are increasingly in demand. The applications on the conductivity range, and materials with electrical conductivity can be applied to electrostatic discharge products $\left(1-10^{11} \mathrm{Ohm} / \mathrm{sq}\right)[1,2]$ and electromagnetic interference products (EMI: 1-10-2 Ohm/sq) [3,4]. As the convergence of fiber and information technology (IT) has accelerated, the various wearable device industry has developed materials with excellent conductivity and the capability to transmit electric signals. For wearable materials including films $[5,6]$, fibers $[7,8]$, and fabrics $[9,10]$, flexibility is crucial to the technical textile industry. Methods to produce conductive fibers include solutions spinning [11], metal coating [12], electrospinning [13,14], bubbfil spinning [15], and melt-spinning [2,16]. Except for melt-spinning, these processes are not suitable for mass production due to high costs and complex manufacturing. Melt-spinning, however, is a cheap mass-production method. In addition, conductive fibers produced by melt-spinning exhibit excellent fiber mechanical strength compared to the other four methods. Despite these advantages, melt-spinning has not been widely used in industry to produce conductive fibers, because it is difficult to control the mixing ratio, screw speed, feed rate and dispersion conditions. Therefore, research on identifying optimal process conditions is still required.

When producing conductive fibers, there are limiting factors such as tensile strength, washing ability, reliability, and the stability of metal conductive or conductive polymer coated yarn. As such, it is 
necessary to add conductive fillers such as carbon black (CB) $[2,14]$, carbon nanotubes [11,16,17], graphite $[18,19]$, and metal powders [20] to fabricate conductive fibers. $C B$ is one of the most commonly-used fillers for plastics. When $\mathrm{CB}$ is mixed with the polymer matrix, mechanical strength improves and the specific surface area increases, resulting in better electric conductivity. The dispersibility of the filler used in melt-spinning is very important, and CB has better spinnability than other carbon fillers due to its small size. Recently, $\mathrm{CB} /$ polymer conductive composites have been studied in various fields. However, most studies have been limited to the production of polymeric resins and simple physical composites using the original CB. It is therefore necessary to study filler modification to improve dispersion and conductivity in the polymer resin. To modify the filler, Iijima devised a carbon nanotube (CNT) [21], and a method to modify it in sulfuric acid and nitric acid has been widely used [22,23].

A polyphosphoric acid (PPA)/phosphorus pentoxide $\left(\mathrm{P}_{2} \mathrm{O}_{5}\right)$ reaction medium, which efficiently functionalizes $\mathrm{CB}$ while retaining its inherent properties, is well known because it causes inherent surface damage and roughness [24-28]. PPA has sufficient acidity to provide protons to the surface of $\mathrm{CB}$, creating an atmosphere in which the substitution reaction can take place by bonding hydrogen to the surface of hydrogen-free CB. The use of PPA can also lead to electrophilic substitution reactions in the absence of electrons, such as carbon nanomaterials. This was confirmed through reactions with single-walled carbon nanotubes (SWNTs) [28], multi-walled carbon nanotubes (MWNTs) [25,26], and vapor-grown carbon nanofibers (VGCNFs) [27]. A mild PPA/ $\mathrm{P}_{2} \mathrm{O}_{5}$ medium is not only an efficient reaction medium but can also prevent re-aggregation and improve dispersion.

Silver (Ag) exhibits the largest electrical and thermal conductivities among all metals [29]. Therefore, functional nanocomposites with desired properties can be tailored by incorporating Ag nanoparticles into polymers [30]. Ag nanoparticles with a high surface area possess remarkable structural, electronic and thermal properties. Therefore, electrical conductivity can be improved by attaching Ag nanoparticles. In this study, we fabricated fibers using four different types of conductive fillers to the polyethylene terephthalate (PET) matrix through the melt-spinning method and investigated the electrical properties of these fibers. To do so, 4-aminobenzoyl functionalized carbon black (ABCB) was synthesized using a Friedel-Crafts acylation reaction in a PPA $88 \%$ assay $/ \mathrm{P}_{2} \mathrm{O}_{5}$ reaction medium, which can efficiently introduce organic functional groups into $\mathrm{CB}$. Silver-attached carbon black (Ag-ABCB) with $\mathrm{Ag}$ nanoparticles attached to $\mathrm{ABCB}$ was then prepared. The electrical conductivity of fibers using $\mathrm{ABCB}$, $\mathrm{Ag}-\mathrm{ABCB}$, commercialized $\mathrm{CB}$, and $\mathrm{Ag} / \mathrm{CB}$ as conductive fillers was investigated. The functionalization of $C B$ was characterized by elemental analysis (EA), thermogravimetric analysis (TGA), and Fourier transform-infrared (FT-IR) analysis. The crystal structure of Ag nanoparticles was investigated using $\mathrm{X}$-ray photoelectron spectroscopy (XPS) and X-ray diffraction (XRD).

\section{Experiments}

\subsection{Materials}

4-Aminobnezoic acid, PPA ( $83 \% \mathrm{P}_{2} \mathrm{O}_{5}$ assay) and $\mathrm{P}_{2} \mathrm{O}_{5}$ were all obtained from Sigma Aldrich Chemical Inc., St. Louis, MO, USA, and used without any treatment. Methanol was used as-received from Daejung Chemmical \& Matals Co. Ltd., Siheung, Korea with a purity $>99.5 \%$. CB (Ketjen Black EC600JD ${ }^{\circledR}$, Amsterdam, The Netherlands) with a surface area of $1270 \mathrm{~m}^{2} / \mathrm{g}$ and pore volume of $4.8-5.1 \mathrm{~mL} / \mathrm{g}$ (as determined by dibutyl phthalate absorption) was purchased from AkzoNobel. The Ag powder NP-S80 (NTbase, Yongin, Korea) was used. The polymer matrix resin was a commercial grade polymer, and polyethylene terephthalate (PET; JSD588 ${ }^{\circledR}$, Huvis Co., Seoul, Korea) with intrinsic viscosity of 0.64 and melt flow rate of 33.6 was used. All materials were used after vacuum drying at $120^{\circ} \mathrm{C}$ for $6 \mathrm{~h}$ before extrusion for moisture removal.

\subsection{Methods}

\subsubsection{Synthesis of $A B C B$}

4-Aminobenzoic acid (ABAc, $20 \mathrm{~g}$ ), CB (20 g), PPA (83\% $\mathrm{P}_{2} \mathrm{O}_{5}$ assay; $1000 \mathrm{~g}$ ), and $\mathrm{P}_{2} \mathrm{O}_{5}(250 \mathrm{~g})$ were placed in a $2 \mathrm{~L}$ four-neck reactor flask equipped with a high-torque mechanical stirrer in addition 
to nitrogen inlet and outlet taps. The reaction mixture was heated to 50 and $100{ }^{\circ} \mathrm{C}$ for $1 \mathrm{~h}$ each to sufficiently disperse $\mathrm{CB}$ in the medium. Subsequently, the mixture temperature increased to $130^{\circ} \mathrm{C}$ and was further stirred for $48 \mathrm{~h}$. At the end of the reaction, the mixture viscosity slowly increased and excess $\mathrm{H}_{2} \mathrm{O}$ was poured into the final product. The resulting precipitate was poured into distilled water, and the product was collected by filtration. The product was Soxhlet-extracted with $\mathrm{H}_{2} \mathrm{O}$ to remove any residual reaction medium for 3 days, and then with methanol for another 3 days to remove unreacted 4-aminobenzoic acid and possible impurities. Finally, samples were freeze-dried under reduced pressure $(5 \mathrm{mmHg}$ ) and the final black powder (yield: $32.64 \mathrm{~g}, 86.99 \%$ ) was collected. Anal. Calcd. for $\mathrm{C}_{15.81} \mathrm{H}_{6} \mathrm{ON}$ (calculation based on \% yield): $\mathrm{C} 82.98 \% ; \mathrm{H} 2.36 \% ; \mathrm{O} 6.22 \% ; \mathrm{N} 5.44 \%$ and found C $83.49 \%$; H $2.03 \%$; O 9.98\%; N 4.54\%.

\subsubsection{Synthesis of $A g-A B C B$}

The Ag-ABCB nanocomposite was prepared using an established method [31]. First, the ABCB powder $(10 \mathrm{~g})$ was dispersed in $2 \mathrm{~L}$ of ethanol for $1 \mathrm{~h}$ under strong stirring. $\mathrm{AgNO}_{3}(0.1 \mathrm{M})$, a silver precursor, was added to the $\mathrm{Ag}-\mathrm{ABCB}$ nanocomposite mixture in an ice bath, and black suspension became light yellowish. Next, an ice-cold aqueous $\mathrm{NaBH}_{4}(0.2 \mathrm{M})$ solution was added dropwise to the mixture under vigorous magnetic stirring for $2 \mathrm{~h}$. The solution turned dark yellow immediately after adding the $\mathrm{NaBH}_{4}$ solution, indicating that the $\mathrm{NaBH}_{4}$ reduced the ionic silver and stabilized the silver nanoparticles that formed [32]. After the reaction was complete, the final product was washed with water and ethanol several times, then collected by vacuum filtration and freeze-dried under a reduced pressure $(0.5 \mathrm{mmHg})$.

The chemical reaction was the $\mathrm{NaBH}_{4}$ reduction of $\mathrm{AgNO}_{3}$ :

$$
\mathrm{AgNO}_{3}+\mathrm{NaBH}_{4} \rightarrow \mathrm{Ag}+\frac{1}{2} \mathrm{H}_{2}+\frac{1}{2} \mathrm{~B}_{2} \mathrm{H}_{6}+\mathrm{NaNO}_{3}
$$

\subsection{Processing}

A twin-screw extruder (BA-11, Bautek Co., Pocheon, Korea) with a screw diameter of $11 \mathrm{~mm}$ and a $3 \mathrm{~mm}$ nozzle with a length-to-diameter ratio $(\mathrm{L} / \mathrm{D})$ of 3.64 was used to prepare a conductive fiber with conductive filler dispersed in the PET matrix. In this study, PET was used as a polymer matrix. Four conductive fillers were used: pristine $\mathrm{CB}$, chemically functionalized $\mathrm{ABCB}, \mathrm{Ag}-\mathrm{ABCB}$, and physically mixed $\mathrm{Ag}$ power and $\mathrm{CB}(\mathrm{Ag} / \mathrm{CB})(\mathrm{Ag} / \mathrm{CB}=10 / 90 \mathrm{wt} \%)$. Amounts of $0.5,1,2,3,4$, and $5 \mathrm{wt} \% \mathrm{w} C \mathrm{CB}$, $\mathrm{ABCB}, \mathrm{Ag}-\mathrm{ABCB}$, and $\mathrm{Ag} / \mathrm{CB}$ were mixed with each $\mathrm{PET}$ polymer matrix and then conductive filler was injected into the hopper of an extruder. The temperature, screw rotation speed, and feeder speed during extrusion are shown in Table 1. An amount of $3 \mathrm{wt} \%$ was wound up at high speed, but $4 \mathrm{wt} \%$ was difficult to fiberize and thus was wound up manually (Figure 1, Table 1). Sample names are shown as conductive filler/PET_X, where $\mathrm{X}$ is the conductive filler content.

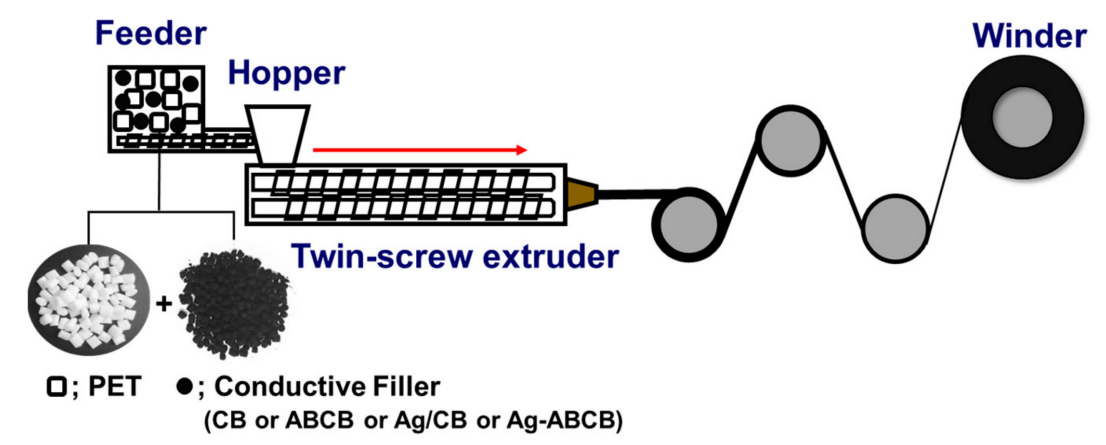

Figure 1. Schematic presentation of the fiber preparation by using melt-spinning process. Conductive fillers used to make conductive fibers are carbon black (CB), amine functionalized carbon black (ABCB), silver-attached carbon black (Ag-ABCB) and Ag/CB. 


\subsection{Characterizations}

EA was completed using Flash 2000 (ThermoScientific, Waltham, MA, USA). FT-IR analysis was performed using Perkin-Elmer, USA. All samples were mixed with dried $\mathrm{KBr}$ and pressed to form semitransparent pellets. TGA was measured using a Q500 (TA Instrument, USA) from room temperature up to $800^{\circ} \mathrm{C}$ at a heating rate of $10^{\circ} \mathrm{C} / \mathrm{min}$ in air. The XRD powder pattern was measured using a D/MAX Ultima II diffractometer with a theta-theta goniometer $(\mathrm{Cu} \mathrm{K} \alpha$ radiation, $\lambda=1.54056 \AA$, Rigaku, Tokyo, Japan) at $40 \mathrm{kV}$, at a scan rate of $2^{\circ} / \mathrm{min}$ for scan angles $2 \theta=10-80^{\circ}$. XPS spectra were obtained from an X-ray photoelectron spectrometer using K-Alpha (Thermo Fisher Scientific, Waltham, MA, USA).

The electrical conductivity of all conductive filler/PET composite fibers was measured using a Keithley $6517 \mathrm{~B}^{\circledR}$ two-point probe high-resistance meter (Keithely Instruments, Inc, Cleveland, OH, USA). All measurements were performed in accordance with the ASTM-D-257 standard resistance measuring method. To measure resistance, the sample was fixed with a silver paste at a distance of $1 \mathrm{~cm}$ on an insulating glass plate, and the resistance was measured after applying $100 \mathrm{~V}$ for $1 \mathrm{~min}$ to stabilize the sample. The electrical conductivity was calculated by the following Equation [33]:

$$
S_{2-\text { point }}\left(\frac{S}{c m}\right)=\frac{1}{V} \times \frac{l}{S} \times \frac{1}{N}
$$

where $V$ is voltage, $l$ is length, $S$ is the cross-sectional area of the fiber, and $N$ is the number of filaments.

Field emission-scanning electron microscopy (FE-SEM; SU8000, Hitachi Ltd. Tokyo, Japan) was used to confirm the synthesized conductive filler morphologies and degree of dispersion in the PET matrix. All samples were cut after pretreatment with liquid nitrogen.

\section{Results and Discussion}

\subsection{Characteristics of $A B C B$ and $A g-A B C B$ Nanocomposites}

To functionalize a carbon material, a carboxyl group must be produced on its surface by treating it with an acid such as a sulfuric acid/nitric acid mixture, and then reacting it with another reactive group. This acid treatment method easily produces a carboxyl group but causes many defects on the carbon material surface $[23,34]$. Unlike the sulfuric acid/nitric acid treatment method, the "direct" Friedel-Crafts acylation reaction can be successfully completed with only a small amount of impurities on the carbon material surface. This method uses a weak acid PPA $/ \mathrm{P}_{2} \mathrm{O}_{5}$ medium to introduce the functional group into the $\mathrm{CB}$ surface, while minimizing the $\mathrm{CB}$ surface damage.

Figure 2 a shows the synthesis of $\mathrm{ABCB}$ by reacting 4-aminobenzoic acid with $\mathrm{CB}$, using the "direct" Friedel-Crafts acylation reaction. This method was first introduced by Baek et al. [24]. When the $\mathrm{ABCB}$ is synthesized by the reaction shown in Figure $2 \mathrm{a}$, the amine group $\left(-\mathrm{NH}_{2}\right)$ is present. Here, $\mathrm{AgNO}_{3}$ was used as a metal salt, and subsequently an Ag attached conductive filler (Ag-ABCB) was reduced by $\mathrm{NaBH}_{4}$. ABCB and $\mathrm{Ag}-\mathrm{ABCB}$ were used as the conductive filler, while the physically-mixed Ag power/CB mixture $(\mathrm{Ag} / \mathrm{CB})$ and commercially available pristine $\mathrm{CB}$ were used as comparative conductive fillers to examine electrical conductivities and morphologies.

EA of the functionalized $\mathrm{ABCB}$ showed that the theoretical value of $\mathrm{CB}$ before reforming was $100.0 \%$, while hydrogen and oxygen content were both $0.0 \%$. However, the analyzed carbon was $97.3 \%$, with a hydrogen and oxygen content of $0.4 \%$ and $0.7 \%$, respectively. Because the CB purity was approximately $99.9 \%$, there were differences between the theoretical and analytical values. The calculated carbon content of functionalized $\mathrm{ABCB}$ was $82.98 \%$, with hydrogen content of $2.36 \%$, oxygen content of $6.22 \%$, and nitrogen content of $5.44 \%$. However, the analyzed carbon content was $83.49 \%$, with hydrogen, oxygen, and nitrogen content of $2.03 \%, 9.98 \%$, and $4.54 \%$, respectively. The following slight differences between calculated and analyzed values were due to the purity of $\mathrm{CB}$ as the starting material: carbon content: $0.51 \%$; hydrogen content: $0.36 \%$; oxygen content: $3.76 \%$; nitrogen content: $0.90 \%$. 
SEM images showed gradual changes during the reaction of pristine $C B, A B C B$, and $A g-A B C B$, with an agglomerate $C B$ and $A B C B$ particle size of approximately $60-70$ and $70-80 \mathrm{~nm}$, respectively (Figure 2c). These results support the functionalization of the 4-aminobenzoyl group. In addition, the bright and white parts indicated by the arrows show that the partially-aggregated silver nanoparticles were well loaded to the $A B C B$ surface (Figure 2d). The Figure $2 d$ inset shows clear Ag peaks from $\mathrm{Ag}-\mathrm{ABCB}$ nanocomposites, visually emphasizing that the Ag nanoparticles were effectively attached to the $A B C B$ surface.

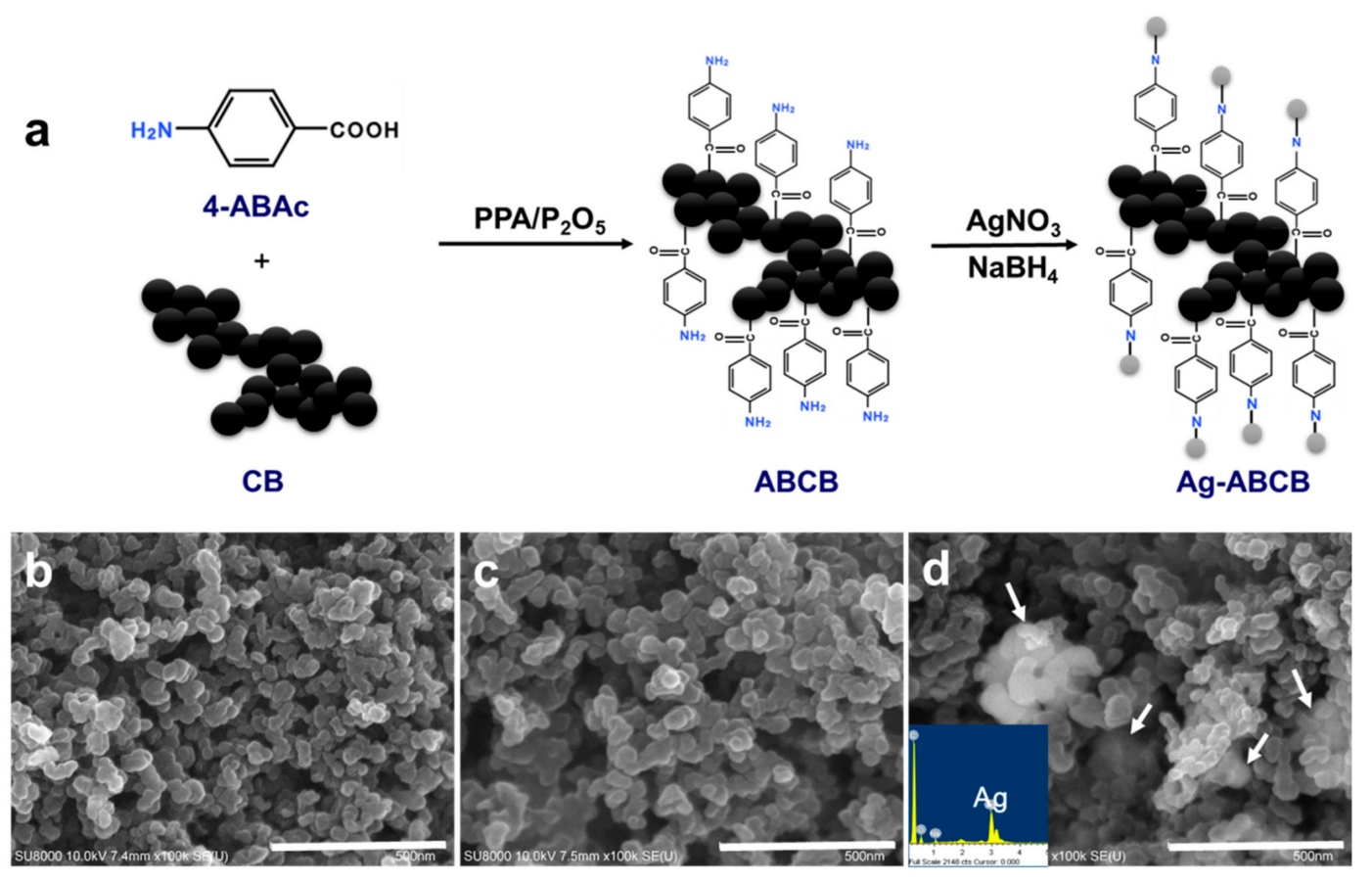

Figure 2. (a) Schematic presentation of the synthesis of $A B C B$ with in $P P A / P_{2} \mathrm{O}_{5}$ medium and $A g-A B C B$ conductive fillers. SEM images of (b) CB; (c) ABCB; (d) Ag-ABCB (Inset is EDX of ABCB). Scale bar is $0.5 \mu \mathrm{m}$.

FT-IR spectroscopy is a very important technique used to study the functionalization of carbon materials. FT-IR was used to confirm that the 4-aminobenzoyl group was efficiently functionalized on the $C B$ surface (Figure 3a). Pristine $C B$ did not exhibit any specific peak, while ABCB showed a primary amine $\left(1603 \mathrm{~cm}^{-1}\right)$. The $\mathrm{CN}$ stretching band of the aromatic amine was $1311 \mathrm{~cm}^{-1}$, and the NH out of the plane bend was $848 \mathrm{~cm}^{-1}$. ABCB also exhibited an aromatic carbonyl $(\mathrm{C}=\mathrm{O})$ peak at $1651 \mathrm{~cm}^{-1}$ [25]. It was therefore confirmed that the 4-aminobenzoyl group was successfully functionalized on the CB surface.

The degree of functionalization and amount of $\mathrm{Ag}$ loaded were quantitatively estimated by TGA. Figure $3 \mathrm{~b}$ shows the thermal stability of $\mathrm{CB}, \mathrm{ABCB}$, and $\mathrm{Ag}-\mathrm{ABCB}$, with the TGA studied from room temperature up to $800{ }^{\circ} \mathrm{C}$ at a heating rate of $10{ }^{\circ} \mathrm{C} / \mathrm{min}$ in air. The weight of pristine $\mathrm{CB}$ did not change up to nearly $600^{\circ} \mathrm{C}$, but a stepwise weight loss occurred in the functionalized ABCB. The initial weight loss at $548{ }^{\circ} \mathrm{C}$ was attributed to the 4 -aminobenzoyl group covalently bonded to the $\mathrm{CB}$ edge. The organic moiety on the $\mathrm{ABCB}$ could be estimated from the weight loss occurring at $548^{\circ} \mathrm{C}$ and was approximately $40 \mathrm{wt} \%$ of the $\mathrm{AB}$ moiety. The pyrolysis that occurred at $664{ }^{\circ} \mathrm{C}$ was attributed to $\mathrm{CB}$. For $\mathrm{Ag}-\mathrm{ABCB}$ in the air, the char yield was approximately $10.5 \mathrm{wt} \%$ at $800{ }^{\circ} \mathrm{C}$, while $\mathrm{CB}$ and $\mathrm{ABCB}$ had values close to $0 \%$. These results were attributable to the $\mathrm{Ag}$ nanoparticle. Overall, TGA results showed that the 4-aminobenzoyl group was covalently attached to the CB surface and the silver nanoparticles were well-attached to the functionalized $A B C B$.

Figure $3 \mathrm{C}$ shows the XRD pattern of the pure $\mathrm{CB}, \mathrm{ABCB}$, and $\mathrm{Ag}-\mathrm{ABCB}$ nanocomposites. The peaks at 24.2 and $43.3^{\circ}$ were attributed to the $C(002)$ and $C(100)$ planes of pristine $C B$, which were crystalline 
graphite-like material [35]. Meanwhile, $\mathrm{ABCB}$ had a peak that was not significantly different from the pristine $C B$ peak. In addition, characteristic diffraction peaks observed at 38.1, 44.3, 64.7, and $77.5^{\circ}$ were attributed to the typical crystallographic planes of $\mathrm{Ag}$ (111), $\mathrm{Ag}$ (200), $\mathrm{Ag}$ (220), and Ag (311) [36]. Ag nanoparticles were strongly bound to the CB surface by amino functionalization, while binding energy between the Ag atom and pure $\mathrm{CB}$ was very weak. Therefore, $\mathrm{Ag}$ nanoparticles bonded strongly to the surface of Ag-ABCB.
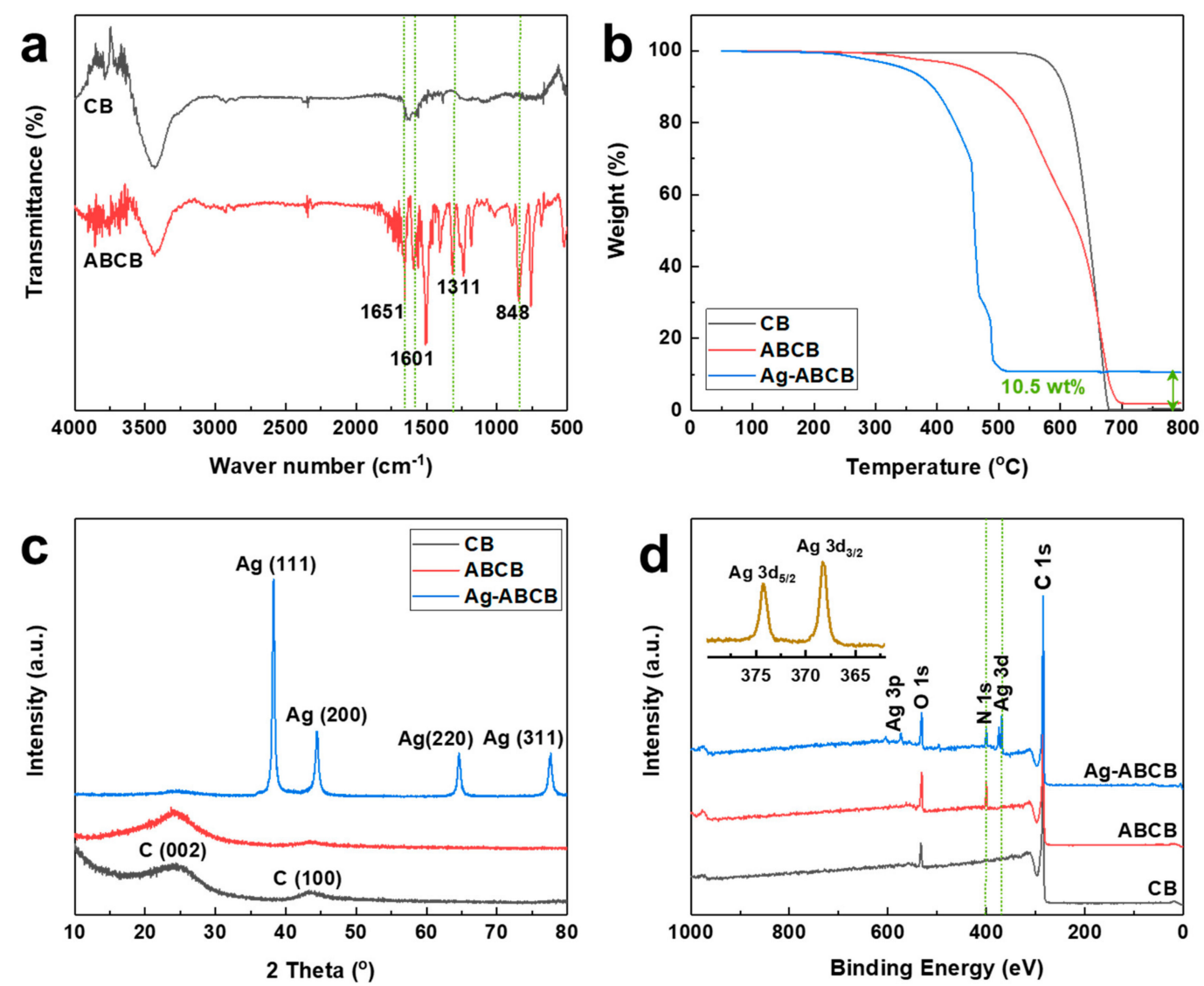

Figure 3. (a) FT-IR spectrum of samples; (b) TGA thermograms of the samples using a heating rate of $10^{\circ} \mathrm{C} / \mathrm{min}$ in air; (c) X-ray powder diffraction patterns of samples; (d) XPS spectra of $\mathrm{CB}, \mathrm{ABCB}$, and Ag-ABCB; High resolution XPS spectra of (inset: Ag3d doublet).

XPS analysis confirmed that the well-functionalized $\mathrm{CB}$ and $\mathrm{Ag}$ attached on the $\mathrm{ABCB}$, exemplified by the presence of $C, O, N$, and $\mathrm{Ag}$ in $\mathrm{Ag}-\mathrm{ABCB}$ (Figure 3d). Pristine $\mathrm{CB}$ exhibited a strong $\mathrm{C}$ 1s peak at $284.5 \mathrm{eV}$, and an $\mathrm{O} 1 \mathrm{~s}$ peak at $532.4 \mathrm{eV}$ [37]. The oxygen element was consistent with the EA findings, and the purity of pristine $\mathrm{CB}$ seemed to be influential. For the 4-aminobenzoyl group, the $\mathrm{N} 1 \mathrm{~s}$ peak was found at $399.8 \mathrm{eV} \mathrm{[38]} \mathrm{in} \mathrm{ABCB}$, and the intensity of the $\mathrm{O}$ 1s peak increased, suggesting that the 4-aminobenzoyl group was successfully functionalized. After attaching the silver nanoparticles, a new peak (Ag 3d) was observed. Ag 3d5/2 $(374.3 \mathrm{eV})$ and $\mathrm{Ag} 3 \mathrm{~d}_{3 / 2}(268.3 \mathrm{eV})$ both exhibited peaks. These peaks were a typical form of $\mathrm{Ag}^{0}$ [39] and strong indicators of the presence of $\mathrm{Ag}$ particles on the ABCB surface.

\subsection{Electrical Properties of Conductive Filler/PET Fiber}

Conductive filler/PET fiber was fabricated by placing the $\mathrm{CB}, \mathrm{ABCB}, \mathrm{Ag}-\mathrm{ABCB}$, and $\mathrm{Ag} / \mathrm{CB}$ into the PET matrix. The temperatures of the six zones were controlled with a twin-screw extruder, and the screw speed and feeder speed were adjusted for each composite (Table 1). 
Table 1. Sample preparation.

\begin{tabular}{|c|c|c|c|c|c|c|c|c|c|c|}
\hline \multirow{2}{*}{ Filler ${ }^{1}$} & \multirow{2}{*}{ PET } & \multicolumn{6}{|c|}{ Temperature $\left({ }^{\circ} \mathrm{C}\right)$} & \multirow{2}{*}{$\begin{array}{l}\text { Screw } \\
\text { Speed } \\
\text { (RPM) }\end{array}$} & \multirow{2}{*}{$\begin{array}{l}\text { Feeder } \\
\text { Speed } \\
\text { (RPM) }\end{array}$} & \multirow{2}{*}{$\begin{array}{l}\text { Winder } \\
\text { Speed } \\
\text { (MPM) }\end{array}$} \\
\hline & & $\begin{array}{c}\text { Zone } \\
\# 1\end{array}$ & $\begin{array}{c}\text { Zone } \\
\# 2\end{array}$ & $\begin{array}{c}\text { Zone } \\
\text { \#3 }\end{array}$ & $\begin{array}{c}\text { Zone } \\
\# 4\end{array}$ & $\begin{array}{c}\text { Zone } \\
\text { \#5 }\end{array}$ & $\begin{array}{c}\text { Zone } \\
\# 6\end{array}$ & & & \\
\hline 0.5 & 99.5 & 200 & 230 & 260 & 260 & 260 & 260 & 110 & 0.80 & 800 \\
\hline 1.0 & 99.0 & 200 & 230 & 260 & 260 & 260 & 260 & 110 & 0.80 & 800 \\
\hline 2.0 & 98.0 & 200 & 230 & 260 & 260 & 260 & 260 & 110 & 0.80 & 700 \\
\hline 3.0 & 97.0 & 200 & 230 & 260 & 260 & 260 & 260 & 110 & 0.80 & - \\
\hline 4.0 & 96.0 & 200 & 230 & 260 & 260 & 260 & 260 & 110 & 0.80 & - \\
\hline 5.0 & 95.0 & 200 & 230 & 260 & 260 & 260 & 260 & 110 & 0.80 & - \\
\hline
\end{tabular}

${ }^{1}$ Filler is $\mathrm{CB}$ or $\mathrm{ABCB}$ or $\mathrm{Ag}-\mathrm{ABCB}$ or $\mathrm{Ag} / \mathrm{CB}$.

To investigate the correlation of electrical conductivity with the type of conductive filler in the fiber, four kinds of conductive fillers $(\mathrm{CB}, \mathrm{ABCB}, \mathrm{Ag}-\mathrm{ABCB}, \mathrm{Ag} / \mathrm{CB})$ were used. The filaments were placed and fixed with silver paste at intervals of $1 \mathrm{~cm}$ (Figure 4 inset). The electrical conductivity of four kinds of fibers was measured a total of 10 times and the average value of these electrical conductivity was used in Figure 4. As shown in Figure 4, the electrical conductivity of the conductive filler/polymer composite fiber was not significantly increased at low CB content, and the electrical conductivity of the conductive composite at the weight ratio of the conductive filler occurred in the range of $4-5 \mathrm{wt} \%$. The electrical conductivity of CB/PET5 was $2.48 \times 10^{-12} \mathrm{~S} / \mathrm{cm}, \mathrm{ABCB} / \mathrm{PET} 5$ was $4.41 \times 10^{-12} \mathrm{~S} / \mathrm{cm}, \mathrm{Ag}-\mathrm{ABCB} / \mathrm{PET} 5$ was $8.41 \times 10^{-8} \mathrm{~S} / \mathrm{cm}$, and Ag/CB/PET5 was $3.48 \times 10^{-11} \mathrm{~S} / \mathrm{cm}$. These results showed that the $\mathrm{Ag}-\mathrm{ABCB} / \mathrm{PET} 5$ fiber had an electrical conductivity approximately $3 \times 10^{4}$ times higher than that of CB/PET5 and $2 \times 10^{3}$ times higher than that of Ag/CB/PET5. The Ag-ABCB/PET5 and $\mathrm{Ag} / \mathrm{CB} / \mathrm{PET} 5$ fibers exhibited a rapid increase in electrical conductivity when the filler content was $4-5 \mathrm{wt} \%$. In particular, the Ag-ABCB conductive filler, which was chemically stably bonded, as opposed to the physically-mixed $\mathrm{Ag} / \mathrm{CB}$ conductive filler, seemed to have a large influence on electrical conductivity improvement.

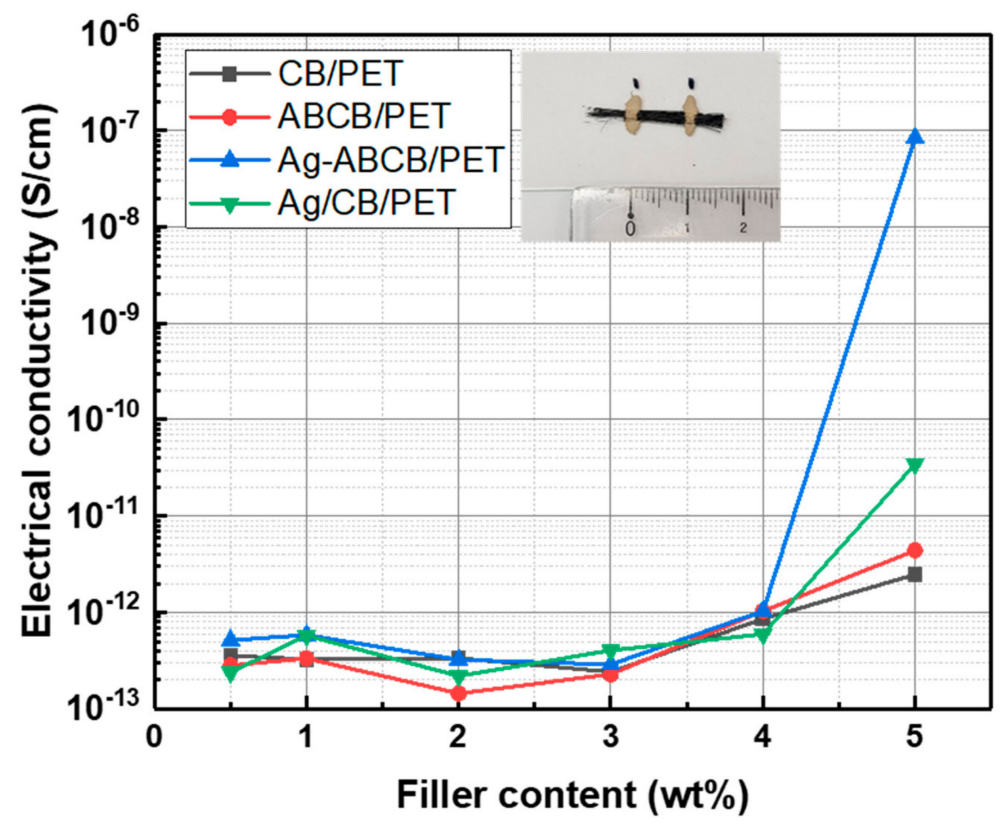

Figure 4. Electrical conductivity of $\mathrm{CB} / \mathrm{PET}, \mathrm{ABCB} / \mathrm{PET}$, Ag-ABCB/PET, and Ag/CB/PET composite fibers.

\subsection{Morphologies of Conductive Filler/PET Fiber}

Electron microscopy was performed to investigate morphology in the PET matrix depending on conductive filler type (Figure 5). The fiber cross section was measured using a conductive filler with a 
content of $5 \mathrm{wt} \%$, in which the electrical conductivity improved sharply. The diameter of CB/PET5 was $79.3 \mu \mathrm{m}$ (Figure 5a), ABCB/PET5 was $69.7 \mu \mathrm{m}$ (Figure 5c), and Ag-ABCB/PET5 was $76.2 \mu \mathrm{m}$ (Figure 5g). To observe the cross section of each fiber in detail, the white square box portion (Figure 5) was magnified and measured. Results showed high electron mobility in the hexagonal layer plane of the CB crystals, indicating electrical conductivity. The electrical conductivity of CB increased as the particle size decreased, and exhibited a high structure. In other words, fibers using $C B$ and $A g / C B$ as conductive fillers displayed small CB particles embedded in the polymer, but the CB particle size increased after the functionalization with $A B C B$, and thus $C B$ was connected (Inset of Figure $5 b, d, h$ ). When the Ag-ABCB conductive filler was used, the conductive filler size was larger than that of pristine $\mathrm{CB}$ (Inset of Figure 5f) and the contact between the Ag-ABCB performed well. These results strongly support the idea that the Ag-ABCB/PET fiber exhibits better electrical conductivity than the CB/PET and $\mathrm{Ag} / \mathrm{CB} / \mathrm{PET}$ fibers.
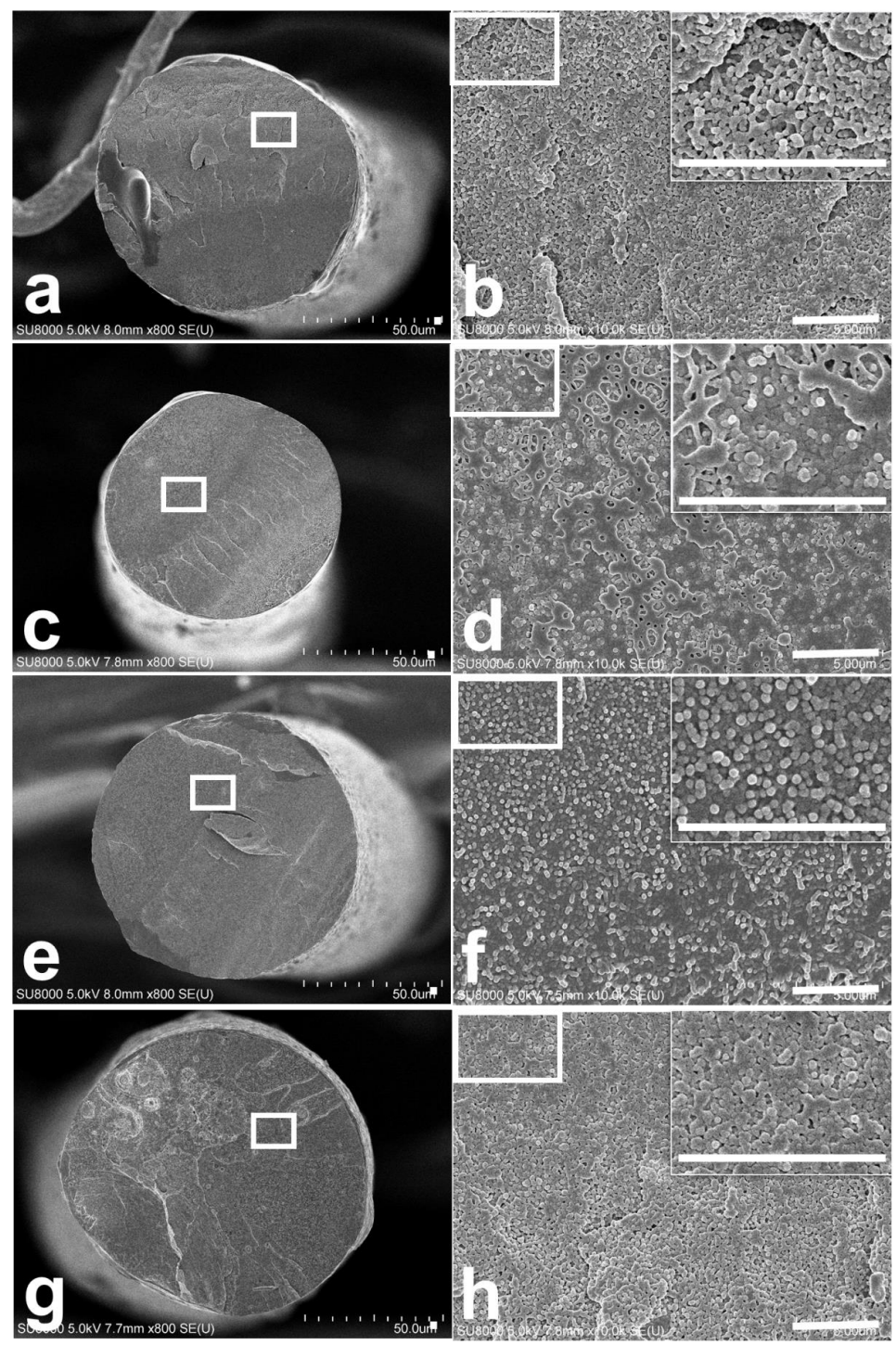

Figure 5. SEM images of (a,b) CB/PET5; (c,d) ABCB/PET5; (e,f) Ag-ABCB/PET5; (g,h) Ag/CB/PET5. Inset, magnified view of a box of $\mathbf{b}, \mathbf{d}, \mathbf{f}$, and $h$. Scale bar is $5 \mu \mathrm{m}$.

\section{Conclusions}

A 4-aminobenzoyl group was functionalized on a CB surface in a PPA/ $\mathrm{P}_{2} \mathrm{O}_{5}$ reaction medium, through the "direct" Friedel-Crafts acylation reaction. Ag-ABCB was prepared using reduced $\mathrm{AgNO}_{3}$ by $\mathrm{NaBH}_{4}$. The morphologies of $A B C B$ and Ag-ABCB were confirmed using SEM images. The ABCB 
nanocomposite exhibited high structure following functionalization with the 4-aminobenzoyl group on $\mathrm{CB}$, and $\mathrm{CB}$ particle size increased with good structure. The Ag nanoparticles were confirmed after loading Ag particles onto the ABCB surface. EA, FT-IR, TGA, XRD and XPS analyses were used to characterize $\mathrm{ABCB}$ and $\mathrm{Ag}-\mathrm{ABCB}$. The electrical conductivities of Ag-ABCB/PET5 fibers were $8.41 \times 10^{-8} \mathrm{~S} / \mathrm{cm}$, approximately $3 \times 10^{4}$ and $2 \times 10^{3}$ times higher than that of $\mathrm{CB} / \mathrm{PET} 5$ and $\mathrm{Ag} / \mathrm{CB} / \mathrm{PET}$, respectively. The chemically functionalized $\mathrm{Ag}-\mathrm{ABCB}$ was much more stable than mechanically-mixed $\mathrm{Ag} / \mathrm{CB}$, and $\mathrm{Ag}$ particles played a major role in enhancing the electric conductivity. Overall, results indicated that our newly developed Ag- $\mathrm{ABCB}$ conductive filler could be used as a conductive fiber. It is expected to be used in a variety of conductive fiber applications, such as antistatic materials and sensors.

Author Contributions: Conceptualization, H.-J.C and S.Y.Y.; Data curation, H.-J.C. and D.A.; Investigation, H.-J.C and D.A.; Formal analysis, H.-J.C.; Writing original draft, H.-J.C; Writing-review and editing, S.L.; S.Y.Y.; Funding acquisition, S.Y.Y. Supervision, S.Y.Y.

Funding: This research was financially supported by Ministry of Trade, Industry and Energy of Republic of Korea (10048884).

Conflicts of Interest: The authors declare no conflicts of interest.

\section{References}

1. Hu, C.C.; Chang, S.S.; Liang, N.Y. Preparation and Characterization of carbon black/polybutylene terephthalate/polyethylene terephthalate antistatic fiber with sheath-core structure. J. Text. I. 2015, 08, 976-984. [CrossRef]

2. Choi, H.J.; Kim, M.S.; Ahn, D.; Yeo, S.Y.; Lee, S. Electrical percolation threshold of carbon black in a polymer matrix and its application to antistatic fibre. Sci. Rep. 2019, 9, 6338. [CrossRef] [PubMed]

3. Kumar, P.; Shahzad, F.; Yu, S.; Hong, S.M.; Kim, Y.H.; Koo, C.M. Large-area reduced graphene oxide thin film with excellent thermal conductivity and electromagnetic interference shielding effectiveness. Carbon 2015, 94, 494-500. [CrossRef]

4. Abbasi, H.; Antunes, M.; Velasco, J.I. Recent advances in carbon-based polymer nanocomposites for electromagnetic interference shielding. Prog. Mater. Sci. 2019, 103, 319-373. [CrossRef]

5. Ren, H.; Zheng, L.; Wang, G.; Gao, X.; Tan, Z.; Shan, J.; Cui, L.; Li, K.; Jian, M.; Zhu, L.; et al. Transfer-mediumfree nanofiber-reinforced graphene film and application in wearable transparent pressure sensors. ACS Nano 2019, 13, 5541-5548. [CrossRef] [PubMed]

6. Zhao, X.; Yang, S.Y.; Cui, N.; Zhao, P.; Tang, Q.; Tong, Y.; Liu, Y. Enhancing the intrinsic stretchability of micropatterned gold film by covalent linkage of carbon nanotubes for wearable electronics. ACS Appl. Electron. Mater. 2019. [CrossRef]

7. Zeng, W.; Shu, L.; Li, Q.; Chen, S.; Wang, F.; Tao, X.-M. Fiber-based wearable electronics: A review of materials, fabrication, devices, and applications. Adv. Mater. 2014, 26, 5310-5336. [CrossRef]

8. Lee, J.; Kwon, H.; Seo, J.; Shin, S.; Koo, J.H.; Pang, C.; Son, S.; Kim, J.H.; Jang, Y.H.; Kim, D.E.; et al. Conductive fiber-based ultrasensitive textile pressure sensor for wearable electronics. Adv. Mater. 2015, 24, 2433-2439. [CrossRef]

9. Zhang, M.; Gao, T.; Wang, J.; Liao, J.; Qui, Y.; Yang, Q.; Xue, H.; Shi, Z.; Zhao, Y.; Xiong, Z.; et al. A hybrid fibers based wearable fabric piezoelectric nanogenerator for energy harvesting application. Nano Energy 2015, 13, 298-305. [CrossRef]

10. Youssefi, M.; Fanaei, E.; Shanbeh, M. Strain sensors on electroless Ni-P plated polyester woven fabrics. Faber. Polym. 2019, 20, 562-568. [CrossRef]

11. Behabtu, N.; Young, C.C.; Tsentalovich, D.E.; Kleinerman, O.; Wang, X.; Ma, A.W.K.; Bengio, E.A.; Waarbeek, R.F.; Jong, J.J.; Hoogerwerf, R.E.; et al. Strong, Light, Multifunctional fibers of carbon nanotubes with ultrahigh conductivity. Science 2013, 339, 185-186. [CrossRef] [PubMed]

12. Li, Y.; Hua, Z.; Yan, F.; Gang, P. Metal coating of fiber gragg grating and the temperature sensing character after metallization. Opt. Fiber Technol. 2009, 391-397. [CrossRef]

13. Pinto, J.J.; Carrión, P.; Quiñones, J.X. Electroless deposition of nickel on electrospun fibers of 2-acrylamido-2methyl-1-propanesulfonic acid doped polyaniline. Mater. Sci. Eng. A 2004, 336, 1-5. [CrossRef] 
14. Gülercan, D.; Gergin, İ.; Sarac, A.S. Preparation and Electrochemical Performances of graphene oxide/PEDOT and reduced graphene oxide/PEDOT nanofibers and nanocomposites. Fiber Polym. 2018, 19, $2178-2187$.

15. Chen, R.X.; Li, Y.; He, J.H. Bubbfil spinning for mass-production of nanofibers. Therm. Sci. 2014, 18, 1718-1719. [CrossRef]

16. Li, Z.; Luo, G.; Wei, F.; Huang, Y. Microstructure of carbon nanotubes/PET conductive composites fibers and their properties. Compos. Sci. Technol. 2006, 66, 1022-1029. [CrossRef]

17. Eom, J.; Lee, J.H.; Park, S.K.; Jeong, Y.; Park, J.S.; Kim, Y.-H. Highly conductive and stretchable fiber interconnections using dry-spun carbon nanotube fibers modified with ionic liquid/poly(vinylidene fluoride) copolymer composite. Compos. Sci. Technol. 2019, 169, 1-6. [CrossRef]

18. Ma, T.; Gao, H.L.; Cong, H.P.; Yao, H.B.; Wu, L.; Yu, Z.Y.; Chen, S.M.; Yu, S.H. A bioinspired interface design for improving the strength and electrical conductivity of graphene-based fibers. Adv. Mater. 2018, 30, 1706435. [CrossRef]

19. Xu, Z.; Liu, Z.; Sun, H.; Gao, C. Highly Electrically conductive Ag-doped graphene fibers as stretchable conductors. Adv. Mater. 2013, 25, 3249-3253. [CrossRef]

20. Grannam, D.M.; Garland, J.C.; Tanner, D.B. Critical behavior of the dielectric constant of a random composite near the percolation threshold. Phys. Rev. Lett. 1981, 46, 375. [CrossRef]

21. Iijima, S. Helical microtubules of graphitic carbon. Nature 1991, 354, 56-58. [CrossRef]

22. Datsyuk, V.; Kalyva, M.; Papagelis, K.; Parthernios, J.; Tasis, D.; Siokou, A.; Kallitsis, I.; Galiotis, C. Chemical oxidation of multiwalled carbon nanotube. Carbon 2008, 46, 833-840. [CrossRef]

23. Gomari, S.; Ghasemi, I.; Eafandeh, M. Functionalized graphene nanoplates/poly(ethylene oxide) nanocomposites: Correlation between crystallization behavior and mechanical performance. Fiber. Polym. 2017, 18, 2153-2160. [CrossRef]

24. Baek, J.B.; Tan, L.S. Improved syntheses of poly(oxy-1,3-phenylenecarbonyl-1,4-phenylene) and related poly(ether-ketones) using polyphosphoric acid/ $\mathrm{P}_{2} \mathrm{O}_{5}$ as polymerization medium. Polymer 2003, 44, 4135-4147. [CrossRef]

25. Lee, H.J.; Han, S.W.; Kwon, Y.D.; Tan, L.S.; Baek, J.B. Functionalization of multi-walled carbon nanotubes with various 4-substituted benzoic acids in mild polyphosphoric acid/phosphorous pentoxide. Carbon 2008, 46, 1850-1859. [CrossRef]

26. Lee, H.J.; Oh, S.J.; Choi, J.Y.; Kim, J.W.; Han, J.; Tan, L.S.; Baek, J.B. In situ synthesis of poly(ethylene terephthalate) (PET) in ethylene glycol containing terephthalic acid and functionalized multiwalled carbon nanotube (MWNTs) as an approach to MWNT/PET nanocomposites. Chem. Mater. 2005, 14, 5057-5064. [CrossRef]

27. Baek, J.B.; Lyons, C.B.; Tan, L.S. Covalent modification of vapor-grown carbon nanofibers via direct Friedel-Crafts acylation in polyphosphoric acid. J. Mater. Chem. 2004, 14, 2052-2056. [CrossRef]

28. Han, S.W.; Oh, S.J.; Tan, L.S.; Baek, J.B. Grafting of 4-(2,4,6-Trimethylphenoxy)benzoyl onto Single-Walled Carbon Nanotubes in in Poly(phosphoric acid) via Amide Function. Nanoscale Res. Lett. 2009, 4, 766-772.

29. Sun, Y.; Xia, Y. Large-scale synthesis of uniform silver nanowires through a soft, self-seeding, polyol process. Adv. Mater. 2002, 14, 833-837. [CrossRef]

30. Lim, S.K.; Lee, S.K.; Hwang, S.H.; Kim, H. Photocatalytic deposition of silver nanoparticles onto organic/inorganic composite nanofibers. Macromol. Mater. Eng. 2006, 291, 1265-1270. [CrossRef]

31. Solomon, S.D.; Bahadory, M.; Jeyarajasingam, A.V.; Rutkowsky, S.A.; Boritz, C. Synthesis and study of silver nanoparticles. J. Chem. Educ. 2007, 84, 322-325.

32. Choi, H.J.; Kang, J.Y.; Jeon, I.Y.; Eo, S.M.; Tan, L.S.; Baek, J.B. Immobilization of platinum nanoparticles on ortho-diaminobenzoyl functionalized multi-walled carbon nanotube and its electrocatalytic activity. J. Nanopart. Res. 2012, 704. [CrossRef]

33. Lim, T.H.; Lee, S.H.; Yeo, S.Y. Highly conductive polymer/metal carbon nanotube composite fiber prepared by the melt-spinning process. Text. Res. J. 2017, 87, 593-606. [CrossRef]

34. Shin, Y.R.; Jung, S.M.; Jeon, I.Y.; Baek, J.B. The Oxidation Mechanism of Highly Ordered Pyrolytic Graphite in a Nitric Acid/Sulfuric Acid Mixture. Carbon 2013, 52, 493-498. [CrossRef]

35. Zakhidov, A.A.; Baughman, R.H.; Iqbal, Z.; Cui, C.; Khayrullin, I.; Dantas, S.O.; Marti, J.; Ralchenko, V.G. Carbon structures with three-dimensional periodicity at optical wavelengths. Science 1998, 2821, 897-901. [CrossRef]

36. Yang, Y.; Liu, E.; Dai, H.; Kang, L.; Wu, H.; Fan, J.; Hu, X.; Liu, H. Photocatalytic activity of Ag-TiÖ-graphene ternary nanocomposites and application in hydrogen evolution by water splitting. Int. J. Hydrog. Energy 2014, 39, 7664-7671. [CrossRef] 
37. Yumitori, S. Correlation of $\mathrm{C} 1$ s chemical state intensities with the O1s intensity in the XPS analysis of anodically oxidized glass-like carbon samples. J. Mater. Sci. 2000, 35, 139-146. [CrossRef]

38. Wei, D.; Liu, Y.; Wang, Y.; Zhang, H.; Huang, L.; Yu, G. Synthesis of N-doped graphene by chemical vapor deposition and its electrical properties. Nano Lett. 2009, 9, 1752-1758. [CrossRef]

39. Potlog, T.; Duca, D.; Dobromir, M. Temperature-dependent growth and XPS of Ag-doped ZnTe thin films deposited by close space sublimation method. Appl. Surf. Sci. 2015, 352, 33-37. [CrossRef] 